\title{
Por que Black Mirror dá muito o que pensar?
}

\author{
Why Black Mirror gives so much to think about? \\ ¿Por qué Black Mirror da tanto en qué pensar?
}

LUCIA SANTAELLA

MARTHA GABRIEL ${ }^{b}$

\section{Resumo}

Já na sua primeira temporada, a série Black Mirror ganhou grande popularidade. As razões para isso são muitas. Entre elas, vale a pena destacar a maneira distópica com que a narrativa desenvolve as questões relativas ao futuro das tecnologias a partir de sinais que já se deixam ver no presente. Para isso, os episódios fazem uso da hipérbole, ou seja, o exagero no tratamento dos temas escolhidos. A internet está repleta de sites e blogs que comentam e buscam as interpretações mais justas para cada um dos episódios que muitas vezes se engendram de maneira bastante engenhosa. O objetivo deste artigo é comparar a exacerbação a que a série conduz os temas tratados com a estratégia composicional dos contos de terror de Edgar Allan Poe. Com isso, pretende-se evidenciar um dos pontos mais fundamentais da montagem narrativa da série de modo a subsidiar sua utilização em contextos educacionais.

Palavras-chave: Distopia. Hipérbole. Montagem. Terror. Uso educacional.

\section{Abstract}

Already in its first season, the Black Mirror series gained great popularity. The reasons for this are many. Among them, it is worth highlighting the dystopian way in which the narrative develops the questions related to the future of technologies from signs that are already visible in the present. For this, the episodes make use of hyperbole, that is, the exaggeration in the treatment of the chosen themes. The internet is full of websites and blogs that comment on and seek the fairest interpretations for each of the episodes that are often ingeniously engendered. The aim of this paper is to compare the exacerbation of

\footnotetext{
a Pontifícia Universidade Católica de São Paulo (PUC-SP), São Paulo, SP, Brasil. Doutora em Teoria Literária, e-mail: Ibraga@pucsp.br

b Pontifícia Universidade Católica de São Paulo (PUC-SP). São Paulo, Brasil. Doutora em Artes, email: Marthagabriel@gmail.com
} 
the series' themes with the compositional strategy of Edgar Allan Poe's horror tales. The intention is to highlight one of the most fundamental characteristics of the series narrative montage in order to subsidize its use in educational contexts.

Keywords: Dystopia. Hyperbole. Montage. Terror. Educational use.

\section{Résumen}

Ya en su primera temporada, la serie Black Mirror ganó gran popularidad. Las razones para esto son muchas. Entre ellas, vale la pena destacar la forma distópica en que la narración desarrolla las preguntas relacionadas con el futuro de las tecnologías a partir de signos que ya son visibles en el presente. Para esto, los episodios hacen uso de la hipérbole, es decir, la exageración en el tratamiento de los temas elegidos. Internet está llena de sitios web y blogs que comentan y buscan las interpretaciones más justas para cada uno de los episodios que a menudo se engendran ingeniosamente. El objetivo de este artículo es comparar la exacerbación de los temas en la serie con la estrategia de composición de los cuentos de terror de Edgar Allan Poe. Por lo tanto, se pretende resaltar uno de los puntos más fundamentales del montaje narrativo de la serie para subsidiar su uso en contextos educativos.

Palabras-clave: Distopia. Hipérbole. Montaje. Terror. Uso educacional

\section{Introdução}

Black Mirror é uma série britânica antológica lançada em 2011, que expõe os impactos insuspeitados que as tecnologias digitais avançadas poderão provocar em nossas vidas futuras. Dado o crescente papel que as tecnologias digitais não cessam de provocar em todas as atividades que desempenhamos, a série obteve uma grande repercussão. De acordo com os especialistas, com os quais as autoras do presente artigo concordam, em seu conjunto, trata-se da melhor obra que desenvolve uma reflexão distópica sobre o assunto. Como o próprio título e sua apresentação insinuam, a proposta é colocar o humano tecnológico diante de um espelho negro em que se estilhaça a imagem que tem de si.

Um dos grandes méritos da série é justamente tentar explorar os impactos não antecipados, ou seja, o outro lado, carente de luz, das tecnologias emergentes. Isso é particularmente importante, porque tendemos a enxergar inicialmente apenas os efeitos previstos de cada tecnologia, negligenciando a reflexão sobre seus possíveis efeitos colaterais. Por exemplo, quando pensamos no surgimento das mídias sociais 
digitais, que inaugurou a fase da Web 2.0, o foco, muitas vezes eufórico, colocava-se em como essas tecnologias poderiam ampliar nossa conexão e interação, inclusive alimentando a convicção sobre a expansão democrática no uso das mídias. Infelizmente, pouco se imaginou na época o quanto isso também colaboraria para a alienação, o vício, as bolhas filtradas responsáveis pela proliferação de fake news e as novas formas de organizar grupos de ações criminosas (SANTAELLA, 2018). Como apontava McLuhan já no século passado, o ser humano cria as tecnologias, e as tecnologias recriam o humano - e nesse processo ela sempre traz tanto impactos benéficos (normalmente relacionadas com a intenção da sua criação), quanto maléficos (muitas vezes, não intencionais e imprevisíveis). Assim, toda e qualquer tecnologia, quando é absorvida pela sociedade, pode produzir efeitos tanto positivos quanto negativos, e inúmeros inesperados.

Muito já se falou e continua a se falar sobre a série. A internet está coalhada de sites de fans prontos a prestar esclarecimentos, quase sempre apaixonados, sobre as prováveis e improváveis interpretações acerca de cada episódio. A preocupação, na maior parte das vezes, reduz-se a justificar que caminho interpretativo é viável se tomar. Isso fica muito claro, por exemplo, em um dos episódios mais complexos da série, White Christmas, no qual a tendência a uma certa abertura de sentidos, justamente essa característica que dá qualidade à série, é levada a níveis maiores de ambiguidade.

Diante disso, a intenção deste artigo é colocar em discussão dois tópicos que parece não terem sido trabalhados anteriormente: a) as analogias que os scripts e a diegese dos episódios apresentam com a estratégia composicional dos contos de terror de Edgar Allan Poe; b) a disforia da série como contraponto às utopias da singularidade, tal como têm disso divulgadas pelos gurus da Universidade da Singularidade na Califórnia. A finalidade da discussão desses tópicos é sinalizar para alguns benefícios e riscos que se podem extrair da série no que diz respeito à educação midiática dirigida aos jovens.

Antes disso, entretanto, para a recordação daqueles que seguiram os episódios e para a introdução daqueles que não tiveram a oportunidade de segui-los, apresentamos abaixo uma breve sinopse de cada episódio. Ademais, o conhecimento do conteúdo é relevante para a discussão que será empreendida mais à frente. 


\section{Sinopse dos episódios}

As duas primeiras temporadas (2011 e 2013) tiveram três episódios cada, mais um episódio especial em 2014. Em 2015, a Netflix comissionou mais 12 episódios — os 6 primeiros foram lançados como terceira temporada da série em 2016. A linguagem usada é orgânica, fazendo com que qualquer discussão apresentada (em muitos casos, beirando a insanidade) pareça natural e parte da vida cotidiana. Cada episódio narra sobre um impacto tecnológico distinto:

Temporada 1 - 3 episódios, lançada 4/dez./2011

- The National Anthem (Ep. 1, Temp. 1) - Considerando que esse episódio foi gravado em 2011, ele traz uma visão bastante possível e instigante do uso das mídias sociais para manipular governos. Uma pessoa sequestra uma princesa na Inglaterra e demanda como condição para liberar a moça que o Primeiro Ministro tenha uma relação sexual com um porco transmitida ao vivo nas mídias. As reflexões sobre o comportamento humano - da mídia, da sociedade e do próprio submetido ministro - causado pelas tecnologias digitais é o ponto alto desse primeiro episódio, pois, ao levar o tema ao absurdo, chama atenção para o poder das mídias sociais para a manipulação e para atentados.

- Fifteen Million Merits (Ep. 2, Temp. 1) — Esse é um dos episódios em que a discussão está voltada para a essência humana. Em um futuro próximo, as pessoas são pagas pela energia que geram ao pedalar bicicletas estacionárias. Um rapaz consegue crédito suficiente para comprar um ticket para a namorada se candidatar a um show de talentos. Quando ela é avaliada pelo júri, eles decidem que ela deve ir trabalhar em um bordel midiático e não em show de músicas. O rapaz fica indignado e pedala dia e noite para conseguir comprar um novo ticket para participar do programa e denunciar a perversidade que está subjacente a tudo isso. No entanto, quando é aprovado no programa e lhe oferecem para ser host em um talk show, ele aceita. Fica aí explícito o cinismo embutido na alienação humana às conveniências do sucesso. 
- The Entire Story of you (Ep. 3, Temp. 1) - Poder gravar e rever em detalhes tudo o que os nossos olhos veem é uma bênção ou maldição? Essa é a discussão desse episódio em que um marido descobre a traição da mulher ao dar replay em suas próprias memórias digitais, exigindo que o amante da mulher delete suas memórias sobre ela, e obrigando a mulher a mostrar as suas memórias. Tudo isso causa transformações tensas na vida de todos. Os impactos afetivos das próteses tecnológicas sobre a memória humana são explorados nesse episódio que, para alguns, é o melhor da série.

Temporada 2 - 3 episódios, lançada 11/fev./2013

- Be Right Back (Ep. 1, Temp. 2) - Seres digitais criados por meio de transferência de informações do ser biológico desenvolvem-se da mesma forma? O que queremos desses seres digitais, assim gerados? Essa é a questão desse episódio, no qual uma viúva resolve reviver o marido em um ser digital que frustra suas expectativas pois não atende à complexidade do marido vivo. Clonagem, vida eterna e robôs com aspirações humanas são as questões centrais do episódio.

- White Bear (Ep. 2, Temp. 2) - Como punir criminosos com tecnologia de forma que paguem seus pecados ao revivê-los indefinidamente (como supostamente seria no inferno) e sofrendo a humilhação da exposição social dos seus erros repetidamente? Esse episódio discute a possibilidade de se criar parques de punição em que o criminoso tem a memória apagada e acorda em um cenário cujas situações o levam a reviver o horror do crime que praticou. Durante o processo, as pessoas do parque freneticamente gravam e transmitem os acontecimentos. Quando eles terminam, a memória da pessoa é novamente apagada e o processo recomeça no parque. Como punir tecnologicamente em uma repaginada sociedade do espetáculo? Este é o eixo do episódio com desdobramentos relativos à manipulação da memória e o circo dos prazeres sociais à maneira dos coliseus romanos.

- The Waldo Moment (Ep. 3, Temp. 2) - Um personagem simulado computacionalmente ganha vida e mais importância no mundo do que a 
pessoa que está por detrás dele. Discute-se aí também a relação entre criador e criatura. Não custa lembrar que, do ponto de vista tecnológico, essa tensão indissolúvel entre humanos biológicos e humanos digitais também foi discutido anteriormente no excelente filme de 2002, SIMONE (SIMulation ONE).

Episódio especial em 16/dez./2014

- White Christmas - Lançado no período de Natal, esse episódio especial é composto por três estórias interconectadas narradas por dois homens isolados em um local remoto gelado. As narrativas refletem sobre a humanidade de como tratamos as pessoas — físicas ou digitais. Se essa época do ano normalmente é dedicada a isso, Black Mirror honra a tradição por meio de suas lentes amplificadas pela distopia tecnológica. Uma das questões centrais desse episódio gira em torno de um dispositivo digital conectado nos olhos de todas as pessoas, que ao mesmo tempo em que permite ver pelos olhos de outro indivíduo, também possibilita bloquear totalmente outros seres, tanto no mundo on-line quanto físico, inclusive visualmente. Como desenvolver um relacionamento sem a possibilidade de retomar um diálogo? A segunda questão levantada na trama é a discussão sobre a ética de se clonar consciências digitalmente para, então, escravizá-las, investigá-las ou puni-las — uma consciência clonada é um ser autoconsciente? Ou apenas um sistema computacional? Finalmente, outra provocação que emerge é a relativização e manipulação do tempo em simulações digitais de forma acentuadamente desproporcional em relação ao mundo físico.

Temporada 3 - 6 episódios, lançada 21/out./2016

- Nosedive (Ep. 1, Temp. 3) - Esse se tornou um dos mais famosos episódios de Black Mirror, pois as pessoas se identificam profundamente com o seu contexto muito análogo ao sistema de avaliação do Uber e inúmeros outros aplicativos digitais e que está se generalizando para todas as atividades humanas na China: as pessoas são avaliadas o tempo todo por sistemas sociais, e quando não obtêm avaliações boas, não conseguem ser aceitas em círculos sociais mais altos ou 
passam a não poder usufruir de determinados serviços na sociedade. O episódio revela a tirania e efeitos perversos das avaliações sociais.

- Playtest (Ep. 2, Temp. 3) - Esse episódio discute as possíveis consequências de implantes cerebrais para jogos (e outros fins) e os impactos que eles podem ter no cérebro humano, acionando consequências trágicas devido à simulação e às interfaces cerebrais.

- Shut Up and Dance (Ep. 3, Temp. 3) - Se estamos conectados e expostos, ao mesmo tempo, estamos sendo vigiados e julgados o tempo todo. Esse episódio explora justamente isso, levando, por meio de chantagem, pessoas vigiadas, que cometeram alguma irregularidade, a punir umas às outras, e eventualmente serem presas por esses crimes maiores, e não pelas irregularidades iniciais. Volta aqui a questão dos justiceiros e da vulnerabilidade.

- San Junipero (Ep. 4, Temp. 3) - Como seria se pudéssemos transferir nossas consciências para uma cidade virtual, com o corpo que desejássemos e levando a vida que quiséssemos sem nos preocuparmos com quaisquer consequências? Levaríamos as mesmas virtudes e vícios para esses locais? Todos desejam viver eternamente? Como lidar com relacionamentos no mundo físico e digital? Retorna aqui a tensão irresolvível entre a vida física e a vida emulada.

- Men Against Fire (Ep. 5, Temp. 3) - Mais uma vez o episódio lida com implantes cerebrais, wearables e a manipulação da percepção da realidade por meio dessas tecnologias.

- Hated in the Nation (Ep. 6, Temp. 3) — Dada a atualidade do tema, esse é um dos mais emblemáticos e citados episódios de Black Mirror, em que um hacker cria um enxame de abelhas drones que podem ser configuradas para atacar um ser humano específico, em qualquer lugar que ele esteja - esse ser é escolhido por meio do poder decisório das mídias sociais: alguém que as pessoas detestem. 
Temporada 4 - 6 episódios, lançada 29/dez/2018

- USS Callister (Ep. 1, Temp. 4) — A habilidade dos hackers é aqui levada ao limite do hackeamento humano via DNA, com a finalidade da criação de seres digitais prisioneiros, de acordo com a fantasia de um psicopata. Novamente aqui, como no episódio White Christmas, a discussão sobre autoconsciência de seres digitais volta à tona, sob uma nova perspectiva.

- Arkangel (Ep. 2, Temp. 4) — Neste episódio, a invasão tecnológica da privacidade transpõe todos os limites. Uma mãe superprotetora instala um aplicativo de monitoramento no tablet da filha, e fica obcecada em acompanhar sua vida. Isso acaba em interferências que causam danos no relacionamento. O que se tem aí é o lado do avesso das boas intenções tecnológicas que resultam em catástrofes psíquicas.

- Crocodile (Ep. 3, Temp. 4) - Da mesma forma que no episódio 3, da primeira temporada (The Entire Storie of You), esse episódio discute a questão de implantes tecnológicos em humanos e animais permitindo a gravação de tudo o que veem em uma memória digital implantada no biológico. Nesse episódio, são avaliadas as implicações sociais, pois mesmo involuntariamente pessoas e animais podem testemunhar (e gravar) acontecimentos, tornando-se testemunhas de crimes e alvo de criminosos.

- Hang the DJ (Ep. 4, Temp. 4) — Aqui surgem os sistemas de match de pares — app datings, como o Tinder, por exemplo — trazendo reflexões sobre as possibilidades da simulação computacional da existência como porta que se abre para melhores escolhas.

- Metalhead (Ep. 5, Temp. 4) - Esse é um dos mais emblemáticos episódios de Black Mirror, e normalmente é um dos mais citados para referenciar o que seria um futuro distópico dominado por robôs. Robôs-cachorros (aliás, muito parecidos com um robô existente hoje da Boston Dynamics) se rebelaram contra a humanidade e caçam humanos, deixando claro que, nesse contexto, é impossível vencer essas máquinas — você pode até enganá-las ou matar uma delas, mas elas 
aprendem e se comunicam, evoluindo rapidamente em grupo. Os avanços da robótica com efeitos nefastos são aqui tematizados.

- Black Museum (Ep. 6, Temp. 4) - Como as tecnologias podem permitir o fluxo da "essência" de um indivíduo humano para diversos outros dispositivos: hologramas, objetos e, inclusive, outros humanos. Nesse caso, a questão central é a moral e ética dessas ações, e também, e talvez principalmente, a crueldade humana que se amplia com o poder tecnológico. Esse episódio retoma a questão da espetacularização e possibilidades digitais da punição infinita como uma simulação digital do inferno (também discutida sob outro ângulo no episódio 2 da $2^{a}$ temporada, White Bear). Quais seriam os limites humanos para possibilidades ilimitadas de punição?

Episódio especial - filme, em 28/dez/2018

- Bandersnatch - Filme interativo em que o espectador é convidado a decidir pelos personagens em diversas cenas - em função de cada escolha, a trama se desenvolve de forma diferente. Apesar de lançar a discussão sobre narrativas compartilhadas, simulação computacional vs realidade, viagem no tempo (via sistema computacional, retomando a simulação no passado para obter resultados distintos no futuro) e reflexões sobre os impactos de escolhas, o processo de navegação no filme é extremamente desinteressante e esse tipo de abordagem é um tanto antigo na literatura, mesmo que utilizando outras formas de execução. Uma das autoras deste artigo (Martha Gabriel) navegou por todas as opções simplesmente para testar o sistema — no entanto, durante esse processo, não saia de sua mente que essa era uma forma de colher dados e intenções para determinação de personalidade. Por exemplo, existem cenas em que você tem que tomar decisões difíceis, para ferir outras pessoas, por exemplo - isso diz muito sobre você. Existem especulações (não comprovadas), de que a Netflix possa ter usado esse filme com essa intenção.

Temporada 5 - 3 episódios, lançada 29/dez/2018

- Striking Vipers (Ep. 1, temp. 5) - Esse episódio explora a relação de dois amigos heterossexuais na vida física, que quando se encontram em um jogo de 
realidade virtual de luta, usando avatares de sexos opostos, se tornam amantes ardentes no mundo simulado. O episódio se desenvolve nesse dilema sobre o que é real, o que é virtual, e o quanto essas realidades se misturam e se mútuo interferem.

- Smithereens (Ep. 2, Temp. 5) — A questão central desse episódio são os impactos que os aplicativos sociais trazem para a humanidade, especialmente vício e distração, afetando os indivíduos, resultando eventualmente em morte. Outro ângulo aqui é como nos tornamos transparentes desde os mais mínimos detalhes até o perfilhamento de nossos hábitos, quando usamos qualquer dispositivo digital — que pode ser acessado pelos produtores dos Apps ou, eventualmente, hackeado.

- Rachel, Jack and Ashley Too (Ep. 3, Temp. 5) - Esse é um dos episódios mais engraçados de Black Mirror. Uma boneca/robô possui a cópia da consciência de uma cantora teen famosa, e a relação de amizade e mesmo de dependência se desenvolve entre uma garota e a boneca (estilo do filme HER), permitindo que a boneca levasse a menina a salvar a vida da verdadeira cantora. Apesar do final feliz (não muito compatível com Black Mirror), as questões que envolvem o uso da tecnologia são psicologicamente bastante instigantes.

\#humanidade \#comportamento \#comportamentodigital $\begin{array}{r}\text { Hash tags da série } \\ \text { \#prdemsocial }\end{array}$
\#privacidade \#segurancadainformacao \#manipulacao \#interfacescerebrais
\#wearables \#vidaeterna \#hacking \#drones \#socialmedia \#humanratings \#alienacao
\#etica \#memoriadigital \#genetica \#clonagem \#robos \#simulacao
\#sentidodehumanidade \#criadorvscriatura \#segurancadesistemas

\section{A hipertrofia de traços}

Não parece ser inadequado afirmar que a estratégia, que comanda a diegese, a ação narrativa, dos episódios da série, guarda algumas similaridades com a técnica composicional dos contos de terror de Edgar Allan Poe. Que técnica é essa?

Para produzir o efeito de profundo estranhamento que termina no sentimento de terror, Poe seleciona um traço de caráter de uma personagem e as vicissitudes provocadas pela hipertrofia desse traço comandam toda a ação narrativa. Todos os 
outros traços de personalidade, que comporiam o perfil de uma pessoa relativamente dentro da normalidade, são apagados, restando apenas um traço e apenas um como, por exemplo, o medo, a paixão avassaladora, o espírito da vingança, a sensibilidade exacerbada, o desgaste e a degeneração. Tudo isso em cenários escuros povoados de signos e sinais distantes do cotidiano da vida.

Ora, quando uma personagem é reduzida a um único traço hipertrofiado de caráter, ela não parece mais habitar o planeta que habitamos, pois seu universo oscila entre o onírico e o absurdo. Isso vai conduzindo o efeito de estranhamento e de grotesco que desemboca no terror, justamente porque chega bem perto de nossos medos mais primários: ser enterrado vivo, retornar após a morte, a decrepitude do corpo, etc.

Vale a pena aqui a lembrança do filme Ninfomaníaca, uma mulher viciada em sexo, de Lars von Trier (2013), produção barata que obteve um retorno comercial três vezes maior, mas ainda bastante modesto quando comparado aos gigantescos milhões dos hits de Hollywood. À maneira de Poe (que, aliás, não deve ser casual aparecer citado nos diálogos do filme), a personagem é reduzida tão só e apenas à sua mania de sexo, esta elevada ao limite da perda de quaisquer outros sentidos para a vida. Nem a iminência da morte do pai poderia ser capaz de deter seu vício mesmo que por um lapso de tempo. Portanto, no filme, a personagem desempenha não um papel, mas uma função demonstrativa do que poderia vir a ser uma pessoa se e quando reduzida a uma única dimensão, no caso, a voragem sexual, em detrimento de quaisquer outras. Sob esse prisma, quaisquer interpretações moralizantes sobre o comportamento da personagem não passariam de retórica existencial incabível. Tanto quanto nos contos de Poe, a personagem funciona como um experimento psicológico para explorar até onde pode ir o drama humano. Haveria limite para ele?

Guardadas as diferenças temáticas, as personagens nos episódios de Black Mirror apresentam similaridades com experimentos desse tipo. É por isso que os comentadores costumam dizer que cada episódio trabalha com um tema a que alguns chamam de um conceito. De fato, são personagens que encarnam, dão corpo a uma questão trazida pelos avanços tecnológicos, cuja problemática é elevada à sua potência máxima. Disso resultam efeitos que se aproximam do grotesco, beirando ou 
mergulhando no absurdo, como está exemplarmente demonstrado no episódio da imposição de uma relação sexual do primeiro ministro com um porco.

O exagero, a desproporção, as distorções que são próprias do grotesco cumprem um papel importante quando se trata de provocar o efeito de repulsa diante de uma dada situação. Tal expediente, que é muito usado nos episódios, embute uma intenção crítica com finalidade educativa, ou seja, de alerta para os possíveis riscos que se ocultam por trás de esperados benefícios prometidos pelos avanços tecnológicos que invadem nossos corpos e mentes. São justamente esses recursos composicionais que colocam Black Mirror como o lado negro, que não está previsto nas propaladas conquistas que poderão advir da chamada singularidade tecnológica.

\section{A singularidade \& seus avessos}

Em 1965, I .J. Good, um especialista em estatística britânico, que, aliás, ajudou a desmontar a máquina de guerra hitleriana, no seu artigo sob o título de "Speculations Concerning the First Ultraintelligent Machine" preconizou a existência de uma máquina ultrainteligente, definida como uma máquina que poderia ultrapassar de longe todas as atividades intelectuais de quaisquer mentes humanas, não importa quão inteligentes estas possam ser. Naquela época, em que a inteligência artificial ainda engatinhava com dificuldade, isso soava como mera ficção de uma mente matemática fértil.

Depois disso, Vernor Vinge, matemático e cientista da computação da Universidade de San Diego, fortemente influenciado por Good, em janeiro de 1983, em um artigo publicado na Omni magażine, cunhou pela primeira vez a expressão “singularidade tecnológica”, com a seguinte explicação:

A evolução de inteligência humana levou milhões de anos. Podemos divisar um avanço equivalente em uma fração desse tempo. Quando isso acontecer, a história humana terá alcançado uma espécie de singularidade, uma transição tecnológica tão imprenetrável quanto o espaço-tempo enlaçado no centro de um buraco negro, e o mundo irá em muito ultrapassar nosso entendimento. Essa singularidade, acredito, já está rondando a imaginação de muitos escritores de ficção científica ${ }^{1}$.

\footnotetext{
${ }^{1}$ Cf. <https://www.singularityweblog.com/when-vernor-vinge-coined-the-technological-singularity/>.
} 
Em 1986, Vinge publicou o livro de ficção científica, Marooned in Realtime, que tematiza a questão da singularidade e que tem inspirado filmes do tipo Mad Max. Então, em 1993, foi publicado seu artigo sobre "The Coming Technological Singularity: How to Survive in the Post-Human Era"2. A partir disso, a expressão atraiu a atenção de outros cientistas até se tornar corriqueira entre eles e hoje dar o nome a uma universidade da Califórnia, voltada para a preparação dos humanos para a continuidade disruptiva ininterrupta que virá daqui para frente. O que isso significa? Segundo Chalmers (2010)

\begin{abstract}
O que acontece quando as máquinas se tornam mais inteligentes do que os humanos? Uma visão é que esse evento será seguido por uma explosão de graus cada vez maiores de inteligência, uma vez que cada geração de máquinas cria máquinas mais inteligentes. Isso ficou conhecido como "singularidade". [...] Definamos uma máquina ultrainteligente como aquela capaz de superar todas as atividades de uma mente humana. Dado que o design de máquinas é uma dentre essas atividades intelectuais, uma máquina ultrainteligente seria a última invenção humana. A ideia chave é que uma máquina mais inteligente dos que os humanos será mais apta do que os humanos para o design de máquinas. Portanto, se ela foi projetada por humanos, será capaz de projetar máquinas mais inteligentes do que ela mesma. Seguindo o mesmo raciocínio a próxima máquina também será capaz de projetar máquinas mais inteligentes do que si mesma. Se cada máquina, por sua vez, fizer o que está capacitada para fazer, pode-se esperar uma sequência de máquinas cada vez mais inteligentes.
\end{abstract}

Isso vem sendo chamado de "explosão da inteligência" que, para ser bem entendida, precisa ser combinada com uma outra ideia proposta por Ray Solominoff no seu artigo, de 1985, "The Time Scale of Artificial Intelligence”3, nomeada como "explosão da velocidade" e baseada na evidência de que o crescimento do processamento computacional dobra em intervalos regulares, do que se pode deduzir que assim será indefinidamente. Uma versão suscinta dessa ideia foi elaborada por Eliezer Yudkowsky, em 1996, no seu artigo "Staring at the Singularity", no qual afirma que a velocidade computacional dobra a cada dois anos de trabalho. O que acontece, então, quando computadores baseados em inteligência artificial (IA) estão a cargo da pesquisa?

Cientistas matemáticos são exímios no desenvolvimento do raciocínio teoremático, de modo que seus argumentos parecem irrefutáveis. Tanto é assim que

\footnotetext{
${ }^{2}$ https://edoras.sdsu.edu/ vinge/misc/singularity.html

${ }^{3} \mathrm{http} / / /$ citeseerx.ist.psu.edu/viewdoc/download?doi=10.1.1.680.364\&rep=rep1\&type=pdf
} 
nenhum cientista da computação avançada hoje duvida dessa destinada sequência de fatos: que a explosão da inteligência virá, nem mesmo os oponentes dessa ideia, quando bem informados, chegam a duvidar. A dúvida encontra-se apenas em quando isso se dará, se mais próximo ou mais longínquo no tempo. Também há uma malha de controvérsias sobre qual será o destino humano nesse vórtice de transformações. Desse modo, entre os especialistas já se tornou voz corrente nomear a IA por níveis que se definem, com as siglas em inglês, como vem abaixo:

- $A N I$ - é a inteligência artificial estreita (narrow), apta a perfomar tarefas isoladas como jogar xadrez, fazer previsões e sugestões. No estado da arte atual, este é o nível de IA atingido pela humanidade por enquanto, mesmo quando envolve machine learning (aprendizagem de máquina) e deep learning (aprendizagem profunda).

- AGI - refere-se à inteligência artificial geral, também conhecida como IA que ainda não ultrapassou o nível humano de inteligência.

- $A S I$ - é a superinteligência artificial, mais inteligente do que o intelecto coletivo dos humanos mais inteligentes em todos os campos.

- Grey Goo - refere-se ao cenário hipotético do apocalipse, o fim do mundo que conhecemos, envolvendo robôs autorreplicantes e nanotecnologia molecular em espirais fora do controle que consomem toda a biomassa da Terra para construir replicas de si mesmas. Esse cenário também vem sendo chamado de "ecofagia".

Certamente não são todos os especialista que concordam com esse fim fúnebre. Sem deixar de considerar sua plausibilidade, esta comparece junto a um vasto elenco de cenários possíveis. Tais cenários são brilhantemente tratados, sem respostas peremptórias, no capítulo 5 do livro Life 3.0. Being human in the age of artificial intelligence, de Tegmark (2017).

\section{Qual o papel de Black Mirror no vórtice das transformações tecnológicas?}

Tudo indica que o genial criador de Black Mirror, Charlie Brooker, autor de seus scripts, se mantém muito bem informado sobre as emergências e iminências tecnológicas que envolvem a robótica evolucionária e a IA, tirando proveito dessas informações para colocar as narrativas na ordem do dia dos acontecimentos já existentes e aqueles por vir. 
O tratamento dado por Gabriel (2018) ao estado da arte das tecnologias digitais evidencia que estar bem informado significa reconhecer, sem escapes alienantes, que o ser humano está atravessando a maior transição que quaisquer gerações anteriores tiveram que enfrentar. Tecnologias disruptivas já estão afetando todas as facetas de nossas vidas, todos os negócios, as indústrias, a educação, a política, as artes e, sobretudo, nosso psiquismo, ao colocar em questão o próprio significado do que é ser humano. Não há sinais de que as mudanças serão estacionárias. Ao contrário, passam por acelerações rápidas inquietantes e até mesmo angustiantes.

Diante disso, alguns dos episódios da série já inserem problemáticas correntes, como por exemplo, descobertas de traições de maridos ou mulheres devido ao esquecimento de desinstalação de aplicativos de localização no smartphone (embora, neste caso, seja Freud aquele que pode fornecer explicações pelo esquecimento). Outros episódios insinuam tramas baseadas em determinações presentes que apontam para o futuro. Essa é também uma dentre as inúmeras razões para o sucesso da série. Elas não perdem a verossimilhança externa, mesmo quando beiram o absurdo, justo porque mantêm fielmente a verossimilhança interna, quer dizer, o passo a passo convincente da narrativa rumo a uma lição de vida que dá o laço final na trama.

Com raras exceções, a distopia comanda o jogo, à maneira de experimentações críticas com a conduta humana, algumas vezes, até o limite do insuportável. Sob esse aspecto, a série guarda a memória de narrativas ancestrais, como aquela de Aladim ou aquela do Rei Midas. As maravilhas prometidas pela lâmpada acabam na perda irreversível das alternativas, enquanto a ambição desmedida do Rei termina por conduzi-lo à perda de seu afeto magno.

Certamente, a série tem uma função educativa nos sinais de alerta que aciona. Aponta para os riscos e perigos das tecnologias quando abraçadas acriticamente como uma tábua de salvação contra as frustrações do cotidiano, que deixam de ser enfrentadas e negociadas devido à fuga alienante em fantasias paralisantes.

Entretanto, como afirmou Kurtzweil, um dos gurus da singularidade, em uma mesa redonda, o recolhimento na distopia também produz efeitos negativos. $\mathrm{O}$ primeiro deles encontra-se na crença dicotômica de que humanos e tecnologias se constituem como dois universos perfeitamente separados. Isso traz como 
consequência a negação teimosa da real natureza técnica e tecnológica do humano desde os primórdios de sua existência bípede na biosfera. Uma vez que o outro extremo, a entrega cega às emergências tecnológicas, também produz os efeitos aos quais Black Mirror aponta com precisão cirúrgica, não parece haver outro caminho a não ser a educação prudente para as tecnologias, educação que começa pela atualização formativa dos caminhos encetados pelas tecnologias, com ênfase na avaliação equilibrada das consequências que elas trazem para a nossa humanidade.

\section{Referências}

CHALMERS, D. The singularity: A philosophical analysis. Journal of Consciousness Studies, v. 17, p. 9-10, 2010.

GABRIEL, M. Você, en e os robôs. Pequeno manual do mundo digital. São Paulo: Atlas, 2018.

SANTAELLA, L. A pós-verdade é verdadeira ou falsa? São Paulo: Editora Estação das Letras e Cores, 2018.

TEGMARK, M. Life 3.0. Being human in the age of artificial intelligence. Penguin Books, 2017.

VINGE, V. Marooned in Realtime. New York: Bleu Jay Books, Inc., 1986.

RECEBIDO: 01/09/2019

APROVADO: 10/09/2019
RECEIVED: 09/01/2019

APPROVED: $10 / 09 / 2019$
RECIBIDO: 01/09/2019

APROBADO: 10/09/2019 